\title{
Serum biochemical values in rheumatoid disease
}

\author{
R. COCKEL, M. J. KENDALL, J. F. BECKER, AND C. F. HAWKINS \\ Queen Elizabeth Hospital, Birmingham
}

\begin{abstract}
Rheumatoid disease is a systemic disorder, the widespread extra-articular manifestations of which have been reviewed by Dudley Hart $(1969,1970)$ in his Ellman and Davidson lectures. The tissues clinically involved are those not usually associated with disturbances of metabolism, so that abnormalities of serum chemistry might not be anticipated. Increased use of biochemical investigations in modern medical practice frequently reveals unexpected and unexplained results which may confuse rather than clarify the management of patients. Furthermore, drugs such as salicylates, phenacetin, and corticosteroids used in treatment of rheumatoid disease may complicate the picture. In the present study we have attempted to determine the frequency of serum biochemical abnormalities in rheumatoid disease and to provide explanations for some of the results obtained.
\end{abstract}

\section{Patients}

100 consecutive patients with rheumatoid disease admitted to a general hospital and to a hospital for rheumatic disorders were studied. Their ages ranged from 12 to 75 years and 71 were female. Diagnosis was based upon the accepted clinical, radiographic, and serological criteria. Using the American Rheumatism Association revised criteria (Ropes, Bennett, Cobb, Jacox, and Jessar, 1959), 37 had classical, 54 definite, seven probable, and two possible rheumatoid arthritis.

Comparison of results with those of a matched control group was necessary because serum values differ with age and sex (Roberts, 1967; Whitehead and Carmalt, 1970) and there was a preponderance of middle-aged and elderly females with rheumatoid disease. Selection of the control group was difficult. We required hospital inpatients of similar age and sex, excluding those with diseases which cause recognized biochemical changes whilst not excluding minor disorders which occur in an ageing population. The control patients had been admitted for minor operations such as herniorrhaphy, haemorrhoidectomy, removal of benign neoplasms, excision of varicose veins, and cystoscopy. Selection of names was made randomly through the hospital computer and a few cases were obtained from the records of the urological department.

\section{Methods}

All patients had fourteen biochemical tests performed on a sample of venous blood taken without special preparation on the morning after admission. Values determined were serum glucose, creatinine, urea, sodium, potassium, alkaline phosphatase, bilirubin, albumin, globulin, calcium, glutamic-oxaloacetic transaminase, iron, uric acid, and cholesterol. Serum 5'nucleotidase was also estimated on some samples, when the alkaline phosphatase was found to be raised. Estimations were made by automated techniques in a laboratory established as a research project jointly by the United Birmingham Hospitals and the Ministry of Health (Whitehead and Carmalt, 1969). In addition, the rheumatoid group was examined and classified according to the ARA criteria, a drug history was obtained, blood was taken for estimation of erythrocyte sedimentation rate and Waaler-Rose titre, and the urine was tested for protein.

Normal ranges for the tests performed were based mainly on the Birmingham population (Roberts, 1967). The means and standard deviations of all determinations were calculated for each group and the significance of differences between rheumatoid and control mean values was assessed using Student's ' $t$ ' test. Correlations between results from various pairs of tests were established.

\section{Results}

The biochemical values were expressed in two ways: percentage outside the normal range and the mean values of each determination. Table I shows the normal range for each test in this laboratory and the percentage of abnormal results in the rheumatoid and control groups. We have also included the percentage of abnormal results occurring in over 2,000 consecutive unselected admissions to this hospital (Whitehead and Carmalt, 1969).

Mean values for each estimation (with two standard deviations) and statistical analysis of results are shown in Table II. The means of our matched controls \pm 2 SD (where appropriate) agree 
Table I Percentage abnormal results in 100 rheumatoid patients compared with matched controls and other patients

\begin{tabular}{|c|c|c|c|c|}
\hline Test & $\begin{array}{l}\text { Normal range in healthy } \\
\text { Birmingham population }\end{array}$ & $\begin{array}{l}100 \text { rheumatoid } \\
\text { patients }\end{array}$ & $\begin{array}{l}100 \text { matched } \\
\text { controls }\end{array}$ & $\begin{array}{l}2,000 \text { other } \\
\text { unselected patients* }\end{array}$ \\
\hline Calcium (mg./100 ml.) & $9-10 \cdot 5$ & $\begin{array}{l}20 \text { low } \\
1 \text { high }\end{array}$ & 4 high & $11 \cdot 5$ \\
\hline Albumin (g./100 ml.) & $>3 \cdot 3$ & 25 low & 0 & $8 \cdot 3$ \\
\hline $\begin{array}{l}\text { Alkaline phosphatase } \\
\text { (K.A. units } / 100 \mathrm{ml} \text {.) }\end{array}$ & $<14$ & 26 high & 6 high & $12 \cdot 2$ \\
\hline Globulin (g./100 ml.) & $2 \cdot 0-3 \cdot 5$ & 44 high & $\begin{array}{l}1 \text { low } \\
3 \text { high }\end{array}$ & $\overline{14 \cdot 4}$ \\
\hline Iron $(\mu \mathrm{g} . / 100 \mathrm{ml})$. & $60-200$ & 68 low & $\begin{array}{r}18 \text { low } \\
4 \text { high }\end{array}$ & $25 \cdot 4$ \\
\hline Urea (mg./100 ml.) & $<45$ & 16 high & $6 \overline{\text { high }}$ & $11 \cdot 0$ \\
\hline Creatinine (mg./100 ml.) & $<1 \cdot 3$ & 7 high & 2 high & $11 \cdot 0$ \\
\hline $\begin{array}{ll}\text { Uric acid }(\mathrm{mg} . / 100 \mathrm{ml} .) & \begin{array}{l}\text { Female } \\
\text { Male }\end{array}\end{array}$ & $\begin{array}{l}<7 \cdot 0 \\
<7 \cdot 5\end{array}$ & 8 high & 2 high & $8 \cdot 0$ \\
\hline Sodium (mEq./l.) & $134-147$ & $\begin{array}{l}5 \text { low } \\
2 \text { high }\end{array}$ & 2 high & $5 \cdot 5$ \\
\hline Potassium (mEq./l.) & $3 \cdot 6-5 \cdot 0$ & $\begin{array}{l}6 \text { low } \\
7 \text { high }\end{array}$ & $\begin{array}{l}2 \text { low } \\
6 \text { high }\end{array}$ & $8 \cdot 8$ \\
\hline Glucose (mg./100 ml.) & $50-150$ & 15 high & 6 high & $11 \cdot 5$ \\
\hline Cholesterol (mg./100 ml.) & $100-300$ & 4 high & $7 \overline{\text { high }}$ & $8 \cdot 4$ \\
\hline Bilirubin (mg./100 ml.) & $<1 \cdot 0$ & 1 high & 4 high & $8 \cdot 0$ \\
\hline $\begin{array}{l}\text { Glutamic oxaloacetic transaminase } \\
\text { (units/ml.) }\end{array}$ & $<20$ & 4 high & 4 high & $4 \cdot 1$ \\
\hline
\end{tabular}

* Whitehead and Carmalt (1969)

Table II Mean values $( \pm 2 S D)$ obtained in 100 rheumatoid patients and 100 matched controls, together with statistical analysis using student's ' $t$ ' test

Test

Calcium (mg./100 ml.)

Albumin (g./100 ml.)

Alkaline phosphatase (KA units/100 ml.)

Globulin (g./100 ml.)

Sodium (mEq./l.)

Cholesterol (mg./100 ml.)

Iron $(\mu \mathrm{g} . / 100 \mathrm{ml}$.)

Potassium (mEq./1.)

Urea (mg./100 ml.)

Creatinine (mg./100 ml.)

Uric acid (mg./100 ml.)

Glucose (mg./100 ml.)

Bilirubin (mg./100 ml.)

Glutamic oxaloacetic transaminase (units/ml.)

\begin{tabular}{c} 
Rheumatoid patients \\
\hline $9 \cdot 32( \pm 1 \cdot 62)$ \\
$3 \cdot 53( \pm 1 \cdot 08)$ \\
$13 \cdot 5( \pm 17 \cdot 2)$ \\
$3 \cdot 72( \pm 2 \cdot 06)$ \\
$140 \cdot 7( \pm 8 \cdot 4)$ \\
$215 \cdot 0( \pm 90 \cdot 0)$ \\
$44 \cdot 8( \pm 68 \cdot 0)$ \\
\hline $4 \cdot 29( \pm 0 \cdot 98)$ \\
$39 \cdot 1( \pm 70 \cdot 4)$ \\
\hline $0.96( \pm 1 \cdot 12)$ \\
$4 \cdot 49( \pm 4 \cdot 6)$ \\
$120 \cdot 0( \pm 90 \cdot 0)$ \\
$0.45( \pm 2 \cdot 4)$ \\
$9.64( \pm 23 \cdot 6)$
\end{tabular}

\begin{tabular}{c} 
Matched controls \\
\hline $9 \cdot 75( \pm 0 \cdot 8)$ \\
$4 \cdot 35( \pm 0 \cdot 68)$ \\
$8 \cdot 74( \pm \quad 6 \cdot 2)$ \\
$2 \cdot 75( \pm 0 \cdot 72)$ \\
$142 \cdot 7( \pm 5 \cdot 2)$ \\
$244 \cdot 0( \pm 82 \cdot 0)$ \\
$102 \cdot 0( \pm 96 \cdot 0)$ \\
\hline $4 \cdot 4( \pm 0 \cdot 98)$ \\
$31 \cdot 1( \pm 14 \cdot 3)$ \\
\hline $0.96( \pm 0 \cdot 32)$ \\
$4 \cdot 65( \pm 2 \cdot 4)$ \\
$110 \cdot 0( \pm 74 \cdot 0)$ \\
$0 \cdot 54( \pm 0 \cdot 48)$ \\
$8 \cdot 59( \pm 13 \cdot 6)$
\end{tabular}

Pat 5 per cent.level

$<0.001$

$<0.001$

$<0.001$

$<0.001$

$<0.001$

$<0.001$

$<0.001$

$0.05>\mathrm{P}>0.02$

$0.05>\mathrm{P}>0.02$

NS

NS

NS

NS

NS 
closely with the normal range (Table I). Highly significant differences $(P<0.001)$ were found between the two groups in seven of fourteen tests and a further two showed a significant difference $(0.05>P>0.02)$.

Correlations were sought between calcium and both albumin and alkaline phosphatase, because a low serum calcium may reflect a reduced albumin with loss of ionized calcium, or may occur with a raised alkaline phosphatase as in metabolic bone disease. The correlation coefficients $(r)$ were 0.619 and 0.090 respectively. Thus reduced levels of serum calcium were probably secondary to a reduced serum albumin (Fig. 1). A significant correlation ( $r=$ 0.812 ) was also found between uric acid and urea (shown graphically in Fig. 2), suggesting that hyperuricaemia may be due to renal impairment.

26 rheumatoid arthritic patients had a raised level of serum alkaline phosphatase. 5'nucleotidase was determined on thirteen of these samples and the value was found to be raised ( $>13$ i.u./ml.) in seven.

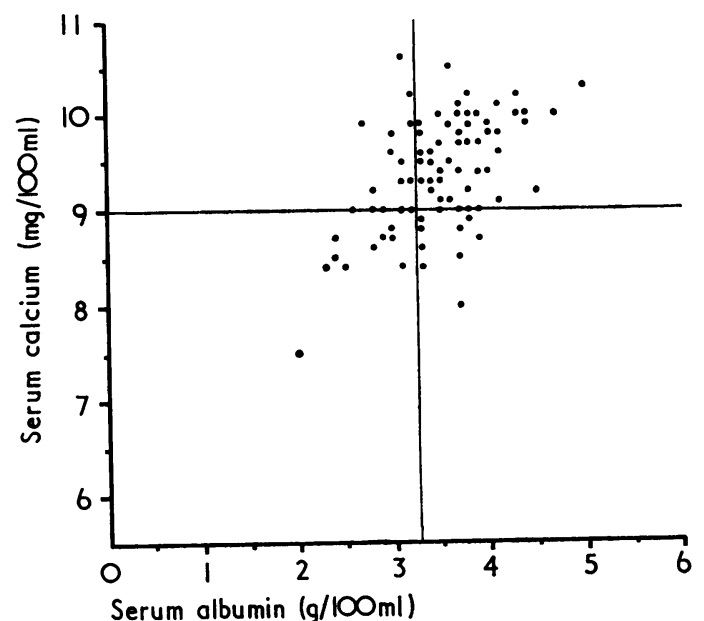

The effects of salicylate and steroid therapy were considered. Thirty patients were taking neither of these, 27 were receiving steroids, 24 salicylates, and eighteen both. The mean values and standard deviations of all fourteen biochemical estimates were calculated for each group. Since the numbers in each treatment group were small and the standard deviations wide, firm conclusions on the effect of these drugs could not be drawn. However, some trends emerged:

(1) Glucose was higher in those receiving steroids alone.

(2) The values for globulin, iron, and cholesterol were less abnormal in those receiving salicylates and/or steroids.

(3) The differences between the groups for the values of uric acid paralleled the changes in urea and creatinine.

Twelve patients had proteinuria, this being only a trace in seven. There was no significant difference between the mean serum albumin in those with heavy or slight proteinuria, although the mean value for the twelve $(3.16 \mathrm{~g} . / 100 \mathrm{ml}$.) was lower than that of the rheumatoid group as a whole. The blood urea was raised in all five patients with heavy proteinuria and in only two of those with a trace.

\section{Discussion}

The incidence of biochemical abnormalities in rheumatoid disease as a whole is unknown. Our results show a high frequency and degree of abnormality in those patients whose disease is severe enough to warrant admission to hospital. The number of abnormal findings implies that the rheumatoid process has widespread metabolic effects over and above the disorders of the locomotor system.

FIG. 1 Relation between serum calcium and serum albumin in 100 rheumatoid patients. Lines indicate lower limits of normal.

FIG. 2 Relation between serum urea and uric acid in 100 rheumatoid patients. Lines indicate upper limits of normal.

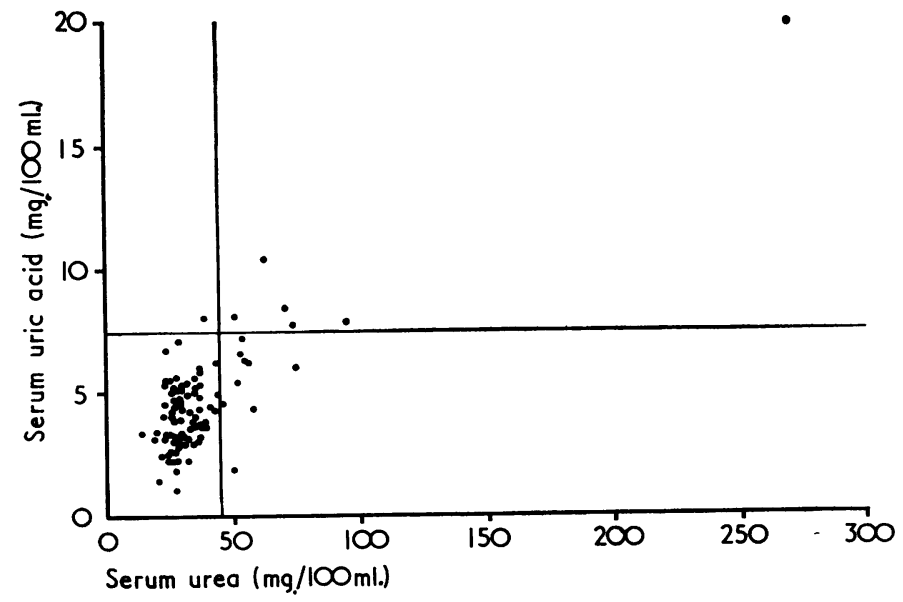


Renal disease was not uncommon as sixteen patients had a raised blood urea and twelve had proteinuria. This has been the experience of others; Lawson and Maclean (1966) found renal abnormalities in 72 per cent. of rheumatoid patients post mortem and Bulger, Healey, and Polinsky (1968) recorded low creatinine clearances in sixteen of their 42 cases. These observations are important, for Duthie, Brown, Truelove, Baragar, and Lawrie (1964) found that 17 per cent. of deaths in rheumatoid disease were due to uraemia. In our cases the cause for the raised urea was unknown; amyloidosis, analgesic nephropathy, interstitial nephritis, arteritis, and glomerulitis have all been reported in post mortem series. Analgesic nephropathy, including interstitial nephritis and papillary necrosis, has been increasingly recognized in recent years and in one post mortem series affected approximately 60 percent. of rheumatoid patients with renal disease (Lawson and Maclean, 1966). Amyloidosis, when clinically manifest, usually exhibits heavy proteinuria, and may be the renal lesion in five of our cases. These two conditions probably account for most instances of renal impairment as there is little evidence in favour of a specific rheumatoid renal lesion (Brun, Olsen, Raaschou, and Sorensen, 1965; Lawson and Maclean, 1966).

Hyperuricaemia is known to occur in some patients with rheumatoid disease, and may lead to an erroneous diagnosis of gout. Dixon (1965) postulated rapid tissue breakdown, salicylate therapy, and 'silent' pyelonephritis as causes. Small doses of aspirin may increase serum uric acid, sometimes to 7 or $8 \mathrm{mg}$. $/ 100 \mathrm{ml}$. because of reduced urinary excretion (Yü and Gutman, 1959), whereas large amounts are uricosuric. In practice, the exact intake of aspirin in these patients is often impossible to determine. No significant difference in the serum uric acid was found between those who were and were not taking aspirin, though the mean value in the former group was slightly lower. Furthermore, the raised uric acid usually implied renal impairment as shown by the correlation of uric acid with urea (Fig. 2) and creatinine. Indeed, a raised uric acid without alteration in urea and creatinine occurred in only one rheumatoid patient and in two controls.

The high incidence of raised alkaline phosphatase was unexpected, although others (Frank and Klemmayer, 1968) have noted abnormal values in some cases. To find out whether this was due to abnormal bone or liver metabolism, we have related the serum calcium and tests of liver function to alkaline phosphatase. Most of the twenty patients with a low serum calcium showed a low albumin (Fig. 1) rather than a raised alkaline phosphatase, and in only three patients did a low calcium coexist with a raised alkaline phosphatase when the serum albumin was normal. By contrast, there was a relationship with liver function, as a raised alkaline phosphatase was often associated with increased $5^{\prime}$ nucleotidase, an enzyme considered specific to liver disease (Hill and Sammons, 1967). Previous studies (Kendall, Cockel, Becker, and Hawkins, 1970) have shown that activity of the rheumatoid process correlates with alkaline phosphatase, implying that hepatic dysfunction is not uncommon in cases of active rheumatoid disease. Despite this evidence of liver disease, the bilirubin and glutamic oxaloacetic transaminase were consistently normal.

The only results for cholesterol which were outside the normal range were higher than normal. However, the mean value for rheumatoid patients was lower than that for the controls. This was not due to the hypocholesterolaemic effect of salicylates (Hetzel, Charnock, and Lander, 1959) as the mean value of patients off drugs was $197 \mathrm{mg} . / 100 \mathrm{ml}$. compared with $213 \mathrm{mg} . / 100 \mathrm{ml}$. in those receiving salicylates; steroid therapy was associated with a higher mean level of $235 \mathrm{mg} . / 100 \mathrm{ml}$. These changes are all unexplained, although diet or impaired hepatic synthesis may be responsible.

The cause for hypoproteinaemia is uncertain. Reduced synthesis due to dietary inadequacy or liver disease is again probable, as there is no evidence of increased loss via the kidney or alimentary tract in most cases. The catabolic effect of steroids may contribute occasionally, although in our steroidtreated group the mean serum albumin was not significantly different from that of those not receiving these drugs. A raised globulin, especially rheumatoid factor and $\alpha_{2}$ globulin, may be due to the suggested autoimmune nature of the disease.

Mean values for sodium and potassium were lower in rheumatoid patients, although usually within normal ranges. These differences were unexplained and not due to corticosteroids; but these drugs probably caused the raised glucose level as it was most marked in the group of 27 treated with steroids alone.

A low level of serum iron was the most frequent abnormality. This was expected, for typical changes in the kinetics of iron metabolism accompany inflammation from any cause (Cartwright, Hamilton, Gubler, Fellows, Ashenbrucker, and Wintrobe, 1951). In our patients, an inverse relation between the serum iron and disease activity, as judged by the ESR, did emerge; however, there were many exceptions to the general trend, probably because of other variables, such as iron deficiency from gastrointestinal blood loss or malnutrition. Paradoxically, the value of estimating serum iron was greatest when it was normal, for then all other biochemical values were likely to be normal as well. 


\section{Summary}

Fourteen biochemical estimations were performed on the serum of 100 consecutive hospital in-patients with rheumatoid disease, and 100 control patients matched for age and sex. Abnormalities of urea, creatinine, uric acid, calcium, albumin, globulin, alkaline phosphatase, and iron were found three (or more) times as frequently in the rheumatoid group. Additionally, the mean values for sodium, potassium and cholesterol were significantly lower in the rheumatoid patients. The significance of these findings is discussed, and implies the existence of many unrecognized metabolic abnormalities in rheumatoid disease.

We gratefully acknowledge the help and co-operation of Prof. T. P. Whitehead and the Biochemistry Department of the Queen Elizabeth Hospital, Birmingham.

\section{References}

Brun, C., Olsen, T. S., RaAschou, F., And Sørensen, A. W. (1965) Nephron, 2, 65 (Renal biopsy in rheumatoid arthritis).

Bulgrr, R. J., Healey, L. A., And Polinsky, P. (1968) Ann. rheum. Dis., 27, 339 (Renal abnormalities in rheumatoid arthritis).

Cartwright, G. E., Hamilton, L. D., Gubler, C. J., Fellows, N. M., Ashendrucker, H., and Wintrobe, M. M. (1951) J. clin. Invest., 30, 161 (The anaemia of infection. XIII. Studies on experimentally produced acute hypoferraemia in dogs and the relationship of the adrenal cortex to hypoferraemia).

Drxon, A. St. J. (1965) 'Progress in Clinical Rheumatology', p. 264. Churchill, London.

Duthie, J. J. R., Brown, P. E., Truelove, L. H., Baragar, F. D., and LaWrie, A. J. (1964) Ann. rheum. Dis., 23, 193 (Course and prognosis in rheumatoid arthritis).

FRANK, O., AND KLEMMAYER, K. (1968) Z. Rheumaforsch., 27, 142 (Die alkalische serumphosphatase bei erkrankungen des rheumatischen formenkreises und ihre beeinflussung durch kortikosteroide).

HART, F. DUdley (1969) Brit. med. J., 3, 131 (Rheumatoid arthritis: Extra-articular manifestations. Part I). (1970) Ibid., 2, 747 (Rheumatoid arthritis: Extra-articular manifestations. Part II).

Hetzel, B. S., Charnock, J. S., AND Lander, H. (1959) Metabolism, 8, 205 (Metabolic effects of salicylate in man).

Hill, P. G., AND SAmmons, H. G. (1967) Quart. J. Med., 36, 457 (An assessment of 5-nucleotidase as a liver function test).

Kendall, M. J., Cockel, R., Becker, J. F., ANd Hawkins, C. F. (1970) Ann. rheum. Dis., 29, 537 (Raised serum alkaline phosphatase in rheumatoid disease. An index of liver dysfunction?).

Lawson, A. A. H., and Maclean, N. (1966) Ibid., 25, 441 (Renal disease and drug therapy in rheumatoid arthritis).

RoBerTs, L. B. (1967) Clin. chim. Acta, 16, 69 (The normal ranges, with statistical analysis for seventeen blood constituents).

Ropes, M. W., Bennett, G. A., Cobb, S., Jacox, R., and Jessar, R. A. (1959) Ann. rheum. Dis., 18, 49 (American rheumatism association diagnostic criteria for rheumatoid arthritis 1958 revision).

Whitehead, T. P., and Carmalt, M. H. B. (1969) Brit. J. Hosp. Med., vol. 2, Equipment Supplement No. 1, p. 49 (Laboratory screening procedures in clinical biochemistry).

(1970) Personal communication.

Yü, T. F., AND GuTMAN, A. B. (1959) J. clin. Invest., 38, 1298 (Study of the paradoxical effect of salicylate in low, intermediate and high dosage on the renal mechanisms for excretion of urate in man). 